\title{
Impact of Sports Perfectionism on Development of Attitude towards Physical Education of the School-Going Adolescents
}

\author{
Sabyasachi Chatterjee ${ }^{1}$ Somnath Nandy ${ }^{2}$ Samirranjan Adhikari ${ }^{3}$ \\ ${ }^{1,2}$ Research Scholar, Department of Physical Education, University of Kalyani, Kalyani, Nadia, W. B., India, \\ ${ }^{3}$ Assistant Professor in Psychology, Shimurali Sachinandan College of Education, Shimurali, Nadia, W.B., India.
}

\begin{abstract}
There are certainly some psychological factors contributing to the development of attitude towards physical education of the school-going adolescents. Here, Sports Perfectionism (Personal Standards, PS; Concern Over Mistakes, COM; Perceived Parental Pressure, PPP \& Perceived Coach Pressure, PCP) were considered to have effect on the development of attitude towards physical education. The study was carried out through descriptive survey method within ex-post-facto research design. A sample of 273 adolescents ( 98 female \& 175 male) was chosen from government aided secondary / higher secondary schools of West Bengal by stratified random sampling technique. To collect data "Attitudes toward Physical Education Scale" and "Sport Multidimensional Perfectionism Scale" were administered on the sample. A multiple regression equation to predict the attitude towards physical education was formulated and the equation is:

Attitude $=80.869+0.690 \times$ Personal Standards $+0.060 \times$ Concern Over Mistakes $-0.161 \times$ Perceived Parental Pressure - $0.056 \times$ Perceived Coach Pressure
\end{abstract}

Key Words: Attitude, Sports Perfectionism, Multiple Regression Equation

\section{Attitude Towards The Physical Education}

Student attitudes toward physical education have been under investigation since the 1930's. Traditionally, the purpose of such inquiry has been to identify factors that contribute to positive and negative feelings toward physical education. It is believed that having such information would improve the quality of physical education by allowing teachers to consider student insights when making curricular or programme decisions.

In recent years, there has been an increase in the body of knowledge in physical education in terms of student attitudes. The increase in interest may also be attributed to the influence of attitudes toward future participation in physical activities outside school (Carlson, 1994; Ennis, 1996; Portman, 1995), to student achievement in physical education (Graham, 1995; Lee, 1997; Silverman, 1993; Subramaniam \& Silverman, 2000), and to the availability of knowledge gained about students' attitudes toward physical education for developing curricula (Cothran \& Ennis, 1998).

According to Luke and Cope (1994), programs based on interests and needs have an influence on the efficiency of the teacher in teaching and helping students understand and believe in the importance of physical education and develop positive attitudes. Teacher's behaviour, classroom, family and school administration play a crucial role in the formation of students' attitudes (Aicinena, 1991). According to Fowler (1974), awareness of the primary students on teachers' behaviour enhances positive attitude towards physical education. The findings of Stensaasens suggest that the 7th, 8th and 9th graders developed negative attitude towards teacher-centred learning (Aicinena 1991). It is also important for the students to get into one to one interaction with the teacher to develop positive attitude (Figley, 1985). Hunter's study (1956) suggests that high school grader females are contented with teacher interaction. Therefore, teachers should ensure active student participation in classroom activities (Aicinena, 1991). According to Figley (1985), students adopt negative attitude when the feel that the teacher pays little attention. Physical environment, peer behaviours, evaluation, exercise partner, stages of learning and difficulty level of learning the activities, etc. have an effect on positive attitude development. Crowded classrooms result in negative attitude among students.

Humiliation and hesitation avoids participation. Unnecessary repetition and superficiality have an effect on positive attitude. A study by Machintosh and Albinson (1982) suggests that students who selected physical education adopted positive attitude towards the lessons and school. A study by Haladyna and Thomas (1979), the attitude average of primary school children in physical education, art and music was higher than that in other subjects.

Earl and Stennet (1987) analysed the attitudes of the students towards physical education and health education. Students replied the question why they did not take up physical education and the replies showed that they did not like the activities (64\%), did not like sports (42\%), did not enjoy the lesson (40\%) and did not like the teacher (39\%) (Luke \& Cope, 1994). In a research by Browne (1992) carried out in West Australia, it was emphasized that participation in physical education activities decreased from $44 \%$ to $37 \%$. In a study carried out 
on 103 female students at the age of 12, who did and did not take up physical education, 99\% stated that they liked physical education lesson, $95.2 \%$ found the lesson entertaining and $94.1 \%$ stated they took up this lesson so as to get out of the classroom.95.2\% of the female students who did not take up the physical education lesson stated that other lessons were of more importance for their future careers, $57.3 \%$ stated their programme would not allow, and $39.8 \%$ stated that the exercises they did outside the school were efficient.

Figley (1985) studied the attitude of K-12 level students (high school) and found that the positive attitude was based on the teacher (41.6\%), curriculum (31.2\%), and classroom atmosphere, self-perception and peer behaviours and other, respectively $(27.2 \%)$. According to the same study, negative attitude was found to be based on curriculum (35.6\%), teacher (33.3\%), and classroom atmosphere, and peer behaviours, self-perception, and other, respectively (31.1\%). Findings of Luke and Sinclair (1991) suggest similar results. Luke and Cope (1994) analysed the attitude of 3rd, 7th and 10th graders towards teacher behaviours and content. A scale of 32 items was used in the research and the first three items were about demographic features. In the items 4th $32 \mathrm{nd}$, even numbers were on teacher behaviours and odd numbers on content. According to the questionnaire results numbered as (2), (1), (0), (-1), (-2), the highest averages were students' confidence in teacher's knowledge (1.37), explanations for the task (1.25) and good sampling (1.11). The lowest averages were little attention paid by the teacher to the feelings of the students $(0.51)$, taking responsibility in classroom activities (.66) and communication skills (0.66). Furthermore, positive attitude was observed in all levels and groups on content and teacher behaviours. In the research by Keogh (1962), there was no change in general attitudes (social, physical and emotional) of girls and boys towards physical education.

\subsection{Perfectionism \& Sports Perfectionism}

Perfectionism is traditionally viewed as an enduring personality trait (Hewitt \& Fleet, 1991). There are numerous definitions of perfectionism exit in the general psychology literature (Fleet \& Hewitt, 2002). Perfectionism is defined as maintaining of unrealistically high standard and expectation and critical evaluation of performance. In every works done by Burns (1980), Pacht (1984) the construct perfectionism was described as a negative quality. Burns (1980) described perfectionism as a network of cognitions including expectation, interpretation and evaluation of events. Individuals who possess perfectionist traits generally have excessively high expectations and define this self worth in regards to the achievement or outcome of these events. Burn (1980) further referred to perfectionism as compulsive strain towards impossible goals. Pacht (1984) supported this definition by adding that perfectionism "keeps people in turmoil". Another view of perfectionism which Hollender (1978) described to be a neglected personality traits is "the practice of demanding of oneself or others in a higher quality of performance than is required by situation" Further more, Forst and Colleagues (Frost, Marten, Lahart \& Rosenblate 1990) referred to perfectionism as "the setting of excessively high standards for performance accompanied by an overcritical self evaluation." As well as associated fear of failure is linked with these excessively high standards (Fleet, Hewitt, Blankslein \& Mosher 1991). Overall the concept of perfectionism is used to describe an individual with high expectation for performance which may impact negatively one's perceived self-worth.

Hemanchek (1978) distinguished normal perfectionism from neurotic perfectionism. Normal Perfectionism can be a positive attribute that reflects a healthy pursuit of high standard. Conversely neurotic perfectionism is exhibited by a fear of failure and is associated with some negative implications. This two dimensional view of perfectionism is further supported by Terry-short, Owens and Slade (1995). Frost, Heimberg, Holt, Maltai and Neubauer (1993) who distinguished between adaptive and maladaptive perfectionism can be explained as a positive pursuit towards achievement where as maladaptive perfectionism is concerned with evaluation and is associated with a fear of failure (Enns, Cox, Sareen \& Freeman, 2001).

Empirical researches show that the dimensions of perfectionism are differently associated with a wide variety of psychological emotional and behavioural correlates -

a) From an adaptive - functioning perspective, perfectionism dimensions have been associated with heightened levels of conscientiousness (Hill, Mclntyre \& Bacharach 1997) social-emotional adjustment (Parker1997) and excellence (Gould, Dieffenbach \& Moffett, 2002)

b) From the perspective of maladaptive functioning perfectionism dimensions have associated with heightened anger (Hewitt \& fleet, 1991), Depression (frost et al, 1990) and eating disorders symptoms (Hewitt, Fleet \& Ediger 1995).

Perfection is all about meeting a standard. When a gifted person sets a standard, it is likely to be very high because they have a clearer picture of what perfect would be and more experience meeting and exceeding other people's standards. There are many different aspects of perfectionism (perfectionism researchers have identified over 20), but they can be sorted into three useful groups: self-oriented, other-oriented, and societal imposed. 
Self-oriented perfectionists are the "classic" type - someone who sets impossibly high standards for their performance or behaviour. This person may invest hours working on a project, only to throw out the product and redo the whole project because it is not perfect, though to anyone else it would seem acceptable, even great. This may happen several times over, exhausting the person, wasting their precious time and energy, and eroding their self-esteem. It is not surprising that perfectionism is closely correlated with obsessivecompulsive disorder (Frost \& Dibartolo, 2002). People can also set impossible standards for behaviour, for example trying to be the perfect host, spouse, or friend. Any deviation from this standard causes major selfcriticism, affecting mood and poisoning the very relationships they are trying so hard to preserve.

Emotional perfectionism can be heartbreaking to witness. The person becomes so greatly distressed by the appearance of a certain emotion (anxiety, hostility, vulnerability, anger, to name a few examples) they begin to command themselves never to have it at all. Then, as the emotion appears, they experience it as intolerable and it creates more of the very emotion they are trying to escape. Despite their efforts, the target emotion will continue to bother them unless they completely cut off all awareness of their emotions.

A potentially dangerous type of perfectionism is other-oriented. In this style, perfect behaviour is demanded of other people, organizations and society. This person is likely to become embittered as they realize that no one can ever fulfil their expectations perfectly. This further atrophies their capacity to take risks and withstand disappointment; they end up living a small life without opportunity to grow. Another choice for this type of perfectionist is accept others as long as they are willing to be controlled. Some abusive domestic arrangements grew from a perfectionist with the best intentions who has turned into a tyrant.

Societal imposed perfectionism is the classic "they" that people believe are watching and judging their every move. "They" say that one should not eat chocolate cake for breakfast, "they" say that anyone who got all A's in high school should be a roaring success in the adult world, "they" say that anyone gifted should not make any mistakes. Who are "they"? Often it's a code or dogma that has been internalized, paralyzing the per-son in a way that they may not even be conscious of. Perhaps it's behavioural standards imposed by a religion, or a school system, or a family. For politicians and celebrities, the media can be a huge influence. For gifted kids, societal imposed perfectionism can be a real dilemma. Not only do parents, teachers, and society expect great things of them, there's usually a peer group who gives the opposite message - using your gifts is un-cool, geeky, or nerdy (Galbraith \& Delisle, 1996).

So what's the good news about perfectionism? Wanting to meet high standards and perform to the best of your ability is a natural human drive, especially for the gifted, which often experience a strong entelechy (drive to growth). Some researchers say that there is adaptive and maladaptive perfectionism (Enns \& Cox, 2002). Adaptive perfectionism seems to centre on the increased ability to concentrate on and achieve goals, the way that the person interprets their results, and the general emotional adjustment of the individual. This seems largely subjective and outcome-based.

Perhaps a more useful way to look at it is that perfectionism is a matter of perspective. What is unreasonable and perfectionistic to one person would seem normal and achievable to another. Ellis (2002) hypothesizes that it is only once a wish becomes a demand that the less desirable side of perfectionism is triggered. One can hold a high standard as an ideal, but reduce one's internal demand to meet it. Here are some ideas about how to deal with perfectionism in your own life -

i) Expectations, standards, and accept-able behaviours each person sets for them-selves and others are within their control to change. When one is totally unattached to whether one's standards get met or not, one can make decisions based on what actually happens, not compared to fantasies of perfection. Ask yourself," Would it be fair to apply this standard to a good friend?" If you wouldn't ask it of them, how fair is it to ask it of yourself? Give yourself the unconditional love and acceptance you would extend to others who need your support.

ii) What you can't accept controls you. If all you focus on is what you didn't do perfectly, you are unable to see the many ways you succeed every day. Emotions and feelings are one mark of our humanity. You can have any emotion and choose the way you react to it. Requiring things or people to be different is usually futile in the long term. Concentrate on the positive.

iii) Any endeavour is subject to diminishing returns. The closer one gets to perfection, the more effort it takes to move the last few steps to get to that goal. You can do five things to $80 \%$ perfect, or one thing to $100 \%-$ it's your choice. Sometimes your $80 \%$ is "their" $100 \%$. There are many situations at work or school where quantity or speed is valued more highly than quality.

iv) Socially imposed standards, or memes, are just that. Bringing awareness to the fact that it is an imposition is the first step in deciding whether or not it is relevant. Carefully examine the rationale for a societal imposed standard before making a conscious choice about conforming to it. Valuing your own perceptions and accepting yourself the way you are is critical to your own growth.

v) Making a mistake or screwing some-thing up is the most efficient way to get good feedback. There is a reason that people make prototypes - going through the design process repeatedly and creating a substandard product is the fastest way to success. Give yourself permission to experiment with your life and 
fail continuously in the service of your learning. Failure is an event, not a person. If you fail, you are a winner because you are pushing the edges of your competence, where the most learning can be found.

vi) One day at a time! Perfectionism robs us of enjoying the present, because we are always waiting for the day when we achieve perfection, or beating ourselves up for past mistakes. Take a deep breath and look around you, right now. Try to feel your heart beating. Ignore your mind's chatter, just for a moment. What do you notice?

There are lots of resources and research on measuring perfectionism and its relationship to other conditions such as depression, chronic anxiety, and eating disorders. The relationship between high IQ and perfectionism is still under investigation, with researchers finding both positive and negative relationships.

\section{Objective of the Study}

The study is designed to discern the psychological and social causes contributing to the development of the attitude towards physical education.

\section{Method}

The present study was carried out through descriptive survey method within ex-post-facto research design. The details regarding sample, tools, procedure of data collection and statistical technique are reported as under:

\subsection{Participants}

A sample of 273 adolescents (98 female \& 175 male) was chosen from government and government aided secondary / higher secondary schools of West Bengal by stratified random sampling technique.

\subsection{Research Tool}

The following research tools will be used in the present study for data collection. The tools are selected by applying yardsticks of relevance, appropriateness, reliability, validity and suitability. Brief descriptions of the tools are given hereunder.

\subsubsection{Attitudes Toward Physical Education Scale - Emirian, \& Altay, 2001:}

Demirhan and Altay (2001) develop the "Attitude toward Physical Education Scale" for Turkish students. This is a paper and pencil self-report instrument with a 5-point Likert-type scale with responses ranging from 1 (Strongly Disagree) to 5 (Strongly Agree) summed across 24 items, resulting in a range from 24 to 120 . A score of 24 indicates the most negative attitude; a score of 25-48 indicates a negative attitude; 49-72 a neutral attitude; 73-94 a positive attitude; and 95-120 the most positive attitude.

\subsubsection{Sport Multidimensional Perfectionism Scale (Sport MPS) - Dunn, Causgrove Dunn \& Syrotuik,}

2002:

The Sport-MPS contains 30 items and 4 subscales. The subscales are labelled Personal Standards (PS: 7 items), Concern Over Mistakes (COM: 8 items, Perceived Parental Pressure (PPP: 9 items), and Perceived Coach Pressure (PCP: 6 items,). The instrument is designed to measure how athletes view certain aspects of their competitive experiences in sport. Athletes rate the extent to which they agree with each of the 30 items using a 5 -point Likert-type scale $(1=$ strongly disagree; $5=$ strongly agree $)$. Item scores are averaged within each subscale, with higher scores reflecting higher levels of perfectionism on each dimension.

\subsection{Procedure}

The relevant data on different constructs were collected by administering the above mentioned tools on the subjects under study in accordance with the directions provided in the respective manuals of the tools.

\subsection{Statistical Analysis}

To predict attitude towards physical education a multiple regression equation has been framed. Linear Regression estimates the coefficients of the linear equation, involving one or more independent variables that best predict the value of the dependent variable. Here, we have tried to predict the attitude towards physical education (the dependent variable) from independent variables viz. perceived deprivation (home and school), perceived parenting (mothering and fathering) and different dimensions of Sport Perfectionism.

\subsubsection{The statistics}

Following statistics had been calculated by using SPSS 13.0 software -

For each variable: number of valid cases, mean and standard deviation are the statistics.

For each model: regression coefficients, correlation matrix, part and partial correlations, multiple $R, \mathrm{R}^{2}$, adjusted $R^{2}$, change in $R^{2}$, standard error of the estimate, analysis-of-variance table, predicted values, and residuals are calculated. Also, $95 \%$ confidence intervals for each regression coefficient, variance-covariance 

matrix, variance inflation factor, tolerance, Durbin-Watson test, distance measures (Mahalanobis, Cook, and leverage values), DfBeta, DfFit, prediction intervals, and case wise diagnostics are done.

Plots: scatter plots, partial plots, histograms, and normal probability plots are drawn.

Here we had calculated the regression coefficients and others as shown in tables-1(a), 1(b), 1(c) and 1(d).

\section{Results}

Table - 1(d) shows the regression coefficients of multiple regression equation predicting attitude towards physical education. Here the constant was 80.869 and the coefficients of Personal Standards, Concern Over Mistakes, Perceived Parental Pressure and Perceived Coach were as 0.690, 0.060, (-0.161) and (-0.056) respectively.

Table - 1(a): Variables Entered in Multiple Regression Analysis with Attitude Scores of Male School-going Adolescents as Dependent Variable

\begin{tabular}{|c|c|c|}
\hline Dependent Variable & Variables Entered & Method \\
\hline & $\begin{array}{c}\text { Personal Standards } \\
\text { Concern Over Mistakes } \\
\text { Perceived Parental Pressure } \\
\text { Perceived Coach Pressure }\end{array}$ & Enter \\
\hline
\end{tabular}

Table - 1(b): Model Summary in Multiple Regression Analysis with Attitude Scores of Male School-going Adolescents as Dependent Variable

\begin{tabular}{|c|c|c|c|c|c|c|c|c|}
\hline $\mathbf{R}$ & $\mathbf{R}^{2}$ & Adjusted R $^{2}$ & $\begin{array}{l}\text { Std. Error of } \\
\text { the Estimate }\end{array}$ & & & & \multicolumn{5}{|c|}{ Change Statistics } \\
\cline { 5 - 9 } & & & $\mathbf{R}^{2}$ Change & F Change & $\mathbf{d f}_{\mathbf{1}}$ & $\mathbf{d f}_{\mathbf{2}}$ & $\begin{array}{c}\text { Sig. F } \\
\text { Change }\end{array}$ \\
\hline 0.273 & 0.075 & 0.061 & 9.23 & 0.075 & 5.406 & 4 & 268 & 0.000 \\
\hline
\end{tabular}

Table - 1(c): ANOVA in Multiple Regression Analysis with Attitude Scores of Male School-going Adolescents as Dependent Variable

\begin{tabular}{|c|c|c|c|c|c|}
\hline & Sum of Squares & df & Mean Square & F & Sig. \\
\hline Regression & 1842.731 & 4 & 460.683 & & \multirow{2}{*}{5.406} \\
Residual & 22837.474 & 268 & 85.214 & \\
\hline Total & 24680.205 & 272 & & & \\
\hline
\end{tabular}

Table - 1(d): Coefficients in Multiple Regression Analysis with Attitude Scores of Male Schoolgoing Adolescents as Dependent Variable

\begin{tabular}{|c|c|c|c|c|c|}
\hline \multirow{2}{*}{ Predictors } & \multicolumn{2}{|c|}{$\begin{array}{c}\text { Unstandardized } \\
\text { Coefficients }\end{array}$} & $\begin{array}{c}\text { Standardized } \\
\text { Coefficients }\end{array}$ & \multirow{2}{*}{ t } & \multirow{2}{*}{ Sig. } \\
\cline { 2 - 3 } & $\mathbf{B}$ & Std. Error & $\square$ & & \\
\hline (Constant) & 80.869 & 4.266 & & 18.956 & 0.000 \\
\hline Personal Standards & 0.690 & 0.161 & 0.302 & 4.287 & 0.000 \\
\hline Concern Over Mistakes & 0.060 & 0.135 & 0.032 & 0.447 & 0.655 \\
\hline Perceived Parental Pressure & -0.161 & 0.147 & -0.084 & -1.097 & 0.274 \\
\hline Perceived Coach Pressure & -0.056 & 0.212 & -0.021 & -0.263 & 0.793 \\
\hline
\end{tabular}

Attitude $=80.869+0.690 \times$ Personal Standards $+0.060 \times$ Concern Over Mistakes $-0.161 \times$ Perceived Parental Pressure - $0.056 \times$ Perceived Coach Pressure

Table -1 (d) shows the regression coefficients of multiple regression equation predicting attitude towards physical education. Here the constant was 80.869 and the coefficients of Personal Standards, Concern Over Mistakes, Perceived Parental Pressure and Perceived Coach were as 0.690, 0.060, (-0.161) and (-0.056) respectively.

\section{Discussion And Conclusion}

With linear regression, we can model the relationship of these variables. This is a good model and it can be used to predict the attitude towards physical education.

Personal standard (PS) had positive impact whereas perceived parental pressure (PPP) had negative impact on development of attitude towards physical education. As the personal standard increases the attitude score also increases, but as perceived parental pressure increases the attitude score decreases.

We may conclude that -

(a) If one sets his/her personal standard in sports perfectionism high then obviously his/her attitude towards physical education would also be high. This factor is an intrinsic motivator and that fact is reflected through 
the result. A student, highly motivated towards games and sports, feels a strong willing to go with the physical education. With this logic our present findings may be justified.

(b) Perceived parental pressure towards sports perfectionism acts as an extrinsic motivator. This may be wrongly interpreted by the adolescents. They may feel that their parents are driving them against their will. In adolescence an individual usually imitates his/her role model and also likes to be guided by the peers. Here parental pressure may be disliked. So this may happen that as parental pressure increases attitude decreases.

References

[1] Aicinena, S. (1991). The teacher \& student attitudes toward physical education. The Physical Educator, Late Winter, 28-31.

[2] Burns, D. D. (1980). Feeling Good: The New Mood Therapy. New York: Morrow.

[3] Carlson, T.B. (1995). We hate gym: student alienation from physical education. Journal of Teaching in Physical Education, 14(4),467-477

[4] Cothran, D.J., \& Ennis, C.D. (1998). Curricula of mutual worth: Comparisons of students' \& teachers' curricular goal. Journal of Teaching in Physical Education, 17, 307-326.

[5] Demirhan, G.,\& Altay, F. (2001). Lise birinci sinif ogrencilerinin beden egitimi ve spora ilifkin olfegilI [Attitudes scale of high school first graders toward physical education and sport II]. Spor Bilimleri Dergisi, 12,09-20.

[6] Dunn, J.G.H., Causgrove Dunn, J., \& Syrotuik, D.G. (2002). Relationship between multidimensional perfectionism and goal orientations in sport. Journal of Sport \& Exercise Psychology, 24,376-395.

[7] Earl,L.M., \& Stennett, R.G. (1987). Student attitudes toward physical \& health education in secondary schools in Ontaria. Canadian Alliance of Heath, Physical Education and Recreation, Journal, 53(4), 4-11

[8] Ellis, A, (2002). The Rolo of Irrational Beliefs in Perfectionism. In G.Flett and P. Hewitt (Eds.), Perfectionism: Theory, Research, and Treatment (pp.217-228). American Psychological Association. Washington, D.C.

[9] Ennis, C.D. (1996). Students' experiences in sport-based physical education: (Mare than) apologies are necessary. Quest, 48,453456.373 .

[10] Enns, M.W., \& Cox, B.J. (2002). The Nature and Assessment of Perfectionism: A Critical Analysis. In G.Flett and P. Hewitt (Eds.), Perfectionism: Theory, Research, and Treatment (pp.33-57). American Psychological Association. Washington, D.C.

[11] Figley, G.E.(1985). Determinants of attitude toward physical education. Journal of Teaching in Physical Education, 4 (4), $229-240$.

[12] Flett, G.L. \& Hewitt, P.L. (2002). Perfectionism and maladjustment: An overview of theoretical, definitional \& treatment issues. In G.L. Flett \& P.L. Hewitt (Eds), Perfectionism: Theory, research \& treatment (pp5-31). Washington, DC: American Psychological Association.

[13] Frost, R.O., marten, P.,Lahart, C.\& Rosenblate, R.(1990). The dimensions of perfectionism. Cognitive Therapy and Research, $14,449-468$.

[14] Frost,R.O., \& Dibartolo, P.M., (2002). Perfectionism, Anxiety, and Obsessive-Compulsive Disorder. In G.Flett and P. Hewitt (Eds.), Perfectionism: Theory, Research and Treatment (pp.341-366). American Psychological Association. Washington, D.C.

[15] Galbraith, J. \& Delisle, J. (1996). Friendship vs. Popularity, The Gifted Kids' Survival Guide: A Teen Handbook (pp 215-216)

[16] Gould, D.,Dieffenbach, K., \& Moffett, A.(2002). Psychological characteristics and their development in Olympic champions. Journal of Applied Sport Psychology, 14,172-204.

[17] Graham, G. (1995). Physical Education through students' eyes \& in students' voice: Introduction. Journal of Teaching in Physi cal Education, 14(4), 364-371.

[18] Haladyna, T. \& Thomas, G. (1979). The attitudes of elementary school children toward school \& subject matters. Journal of Experimental Education, 48 (1, 18-23.

[19] Hamachek, D. E. (1978). Psychodynamics of normal and neurotic perfectionism. Unpublished manuscript, Michigan State University at East Lansing.

[20] Hewitt, P.L., \& Flett, G.L. (1991). Perfectionism in the self \& social context: Conceptualization, assessment \& association with psychopathology. 60, 456-470.

[21] Hewitt, P.L., Flett, G.L., \& Ediger,E.(1995). Perfectionism trait and perfectionist self-presentation in eating disorder attitudes, characteristics, and symptoms. International Journal of Eating Disorder, 18, 317-326.

[22] Hill, R.W., McIntire, K., \& Bacharach, V.R. (1997). Perfectionism and the big five factors. Journal of Social Behaviour and Personality, 12, 257-270.

[23] Keough, J. (1962). Analysis of general attitudes toward physical education. Research Quarterly, 33 (2), $239-244$.

[24] Lee, A.M. (1997). Contribution of research of student thinking in physical education. Journal of Teaching in Physical Education, $16,262-277$

[25] Luke, M.D., \& Sinclair, G.D. (1991). Gender differences in adolescents' attitudes toward school physical education. Journal of Teaching in Physical Education, 11(1), 31-46.

[26] Luke, M. D. \& Cope, L.D. (1994). Student attitudes toward teacher behaviour \& programme content in school physical education. The Physical Educator, Spring, 57-66.

[27] Macintosh, D. \& Albinson, J. (1982). Physical education in Ontario Secondary Schools. Canadian Association for Heath, Physical Education \& Recreation Journal, 48(3), 14-17.

[28] Pacht, A. R. (1984). Reflections of perfectionism. American Psychology, 39, 386-390.

[29] Parker, W.D.(1997). An empirical typology of perfectionism in academically talented children. American Educational Research Journal, 34,545-562.

[30] Portman, P.A.(1995). Who is having fun in physical education classes? Experiences of sixth grade students in elementary \& middle schools. Journal of Teaching in Physical Education, 14 (4), 445-453.

[31] Silverman, S. (1993). Student Characteristics, practice \& achievement in physical education. Journal of Educational Research, 87, 54-61

[32] Subramaniam, P.R. \& Silverman, S. (2000). Validation of scores from \& instrument assessing student attitude toward physical education. Measurement in Physical Education \& Exercise science, 4, 29-40.

[33] Terry - Short, L.A., Owens, G.R., \& Slade, P.D. (1995). Positive and negative perfectionism. Personality and Individual Differences, 18, 663-66. 